\title{
THE TITRATION OF VACCINIA VIRUS ON THE CHORIO- ALLANTOIC MEMBRANE OF THE DEVELOPING CHICK EMBRYO
}

\author{
By J. C. N. Westwood, M.B., B.Ch. (Cantab.), Dip. Bact. (Lond.) \\ P. H. PHIPPS, F.I.M.L.T. AND E. A. BOULTER, M.B., B.S. (LoNd.) \\ Microbiological Research Department, Porton, near Salisbury, Wilts
}

(With 1 Figure in the Text)

\section{INTRODLCTION}

The technique of infecting the developing chick embryo by the chorio-allantoic route, introduced by Woodruff \& Goodpasture (1931), was developed by Burnet $(1936 a, b)$ into a general method for the titration of pock-producing viruses, and was applied to vaccinia virus by Keogh (1936). The method is now widely used and is the most accurate available for the titration of vaccinia. Nevertheless, owing to the wide scatter in individual counts from a single virus dilution, its accuracy is far below that of the analogous plate count titration of bacterial suspensions.

This scatter was recognized by Burnet $\&$ Faris (1942), and is well illustrated by the figures published by Fenner \& McIntyre (1956). Burnet \& Faris (1942) attempted to overcome it by suitably weighting their results. On the grounds that marked departure from the expected scatter was always towards a low, rather than a high, count, they doubled the value given to all those membranes which 'could reasonably be regarded as giving counts in the normal range'. This they regarded as the 'least objectionable' way of overcoming the difficulty, but, while it would tend to give a truer estimate of the virus concentration, the procedure is highly undesirable.

Fenner \& McIntyre (1956), working with myxoma virus, accepted the wide scatter as in intrinsic defect in the method due to variation in the susceptibility of egg membranes. They exercised no selection over their data, and their figures show coefficients of variation varying from 28 to $110 \%$, with the majority lying above $60 \%$. In a series of thirty-six titrations of the same material the betweenegg coefficient of variation was $63 \%$. These results are far outside Poissonian expectation.

Reid, Crawley \& Rhodes (1949), using fowl pox virus, are the only workers who have obtained a good fit with Poisson distribution, but their findings were unfortunately restricted to mean counts of less than 15 , below which level the expected coefficient of variation is, in any case, high.

The recent work of Orerman \& Tamm (1956) does not materially contribute to the precision of the technique since they failed to investigate many of the factors affecting the virus count, and their use of a 3 -day period of incubation for inoculated 
eggs led to results which would severely limit the accuracy and usefulness of the method.

We have concentrated on improving the pock-counting technique by attempting to detect and eliminate those factors responsible for the excessive scatter, and then reassessing the precision of which the method is capable. Success has not been complete, but scatter has been reduced to near the limit set by the Poisson distribution

\section{MATERIALS AND METHODS}

Virus

The strain of vaccinia virus used has been passed in rabbit skin since 1937. The virus was prepared as distilled water extracts of rabbit skin pulp which were centrifuged at 3000 r.p.m. for 20 min. The virus concentration in such extracts was about $10^{10}$ infective units $/ \mathrm{ml}$. as measured in eggs, and the concentrated material was stored at $-60^{\circ} \mathrm{C}$. This virus strain was obtained through the courtesy of Prof. A. W. Downie.

$$
\text { Eggs }
$$

White Leghorn eggs from flocks at the Animal Breeding Establishment, Porton, were used for all experiments, and were laid down for incubation within 1 week of being received in the laboratory and within 2 weeks of being laid. They were incubated on end,with their air-sacs uppermost, in a commercial egg incubator set to turn the eggs every $4 \mathrm{hr}$.

\section{Serum}

The normal horse serum for virus diluents was inactivated at $56^{\circ} \mathrm{C}$. for $30 \mathrm{~min}$. before use.

$$
\text { Buffers }
$$

McIlvaine's citric acid/di-sodium phosphate buffer (Clarke, 1928) was used at $0 \cdot 004 \mathrm{M}$ concentration and $\mathrm{pH} 7 \cdot 2$.

Isotonic sodium phosphate buffer, $\mathrm{pH} 7.2$ and molarity $0 \cdot 122$, was also used. and is referred to as 'Hendry' buffer.

\section{Technique of preparing egg for inoculation}

The technique described below is that now in use and is a direct development from that of Burnet \& Faris (1942) as a result of the work reported in this paper.

Eggs. Embryos were inoculated at the 12 th day of incubation.

First candling. A $100 \mathrm{~W}$. bulb was so housed as to shine from above through one end of the egg. The egg was first candled with the pointed end upwards and the albumin sac located; it was then reversed to bring the air-sac uppermost and marked for drilling on the side opposite to the ablumin sac, usually in relation to the upper allantoic vein, at a point as free as possible from blood vessels. Candling from the pointed end also made it easy to detect those embryos with retarded development of the chorio-allantoic membrane, and such embryos were not used.

Drilling. Eggs were drilled with a $\frac{7}{8}$ in. diamond impregnated wheel, making a cut about $\frac{1}{16}$ in. in width. The wheel was mounted in a $\frac{1}{4}$ h.p. induction motor revolving at 1470 r.p.m., and rigidly fixed to the bench. The egg was held in both 
hands and applied to the drill. The drill was not applied to the egg as is the case when a hand-held drill is used. This point is of crucial importance since it allows fine control of the pressure applied and of the depth of the cut. The drill was allowed to cut into the shell at a single point only, making an oval cut about $\frac{1}{8} \mathrm{in}$. long and $\frac{1}{16}$ in. wide, of such a depth that a powdering of shell still remained on the surface of exposed shell membrane. In this way injury to the chorio-allantoic membrane was avoided, and, in our hands, this technique has proved more satisfactory than that devised by Nadeje, Tamm \& Overman (1955).

Dropping the membrane. $0.1 \mathrm{ml}$. of $0.004 \mathrm{M} \mathrm{Mcllvaine} \mathrm{buffer}$ at $50^{\circ} \mathrm{C}$. was placed on the cut in the shell and through it the membrane was split by downward traction with a needle as described by Beveridge \& Burnet (1946). Separation of the membrane was then initiated by sucking air from the air-sac, with the utmost gentleness, through a hole drilled for this purpose. As soon as separation was started, the split in the shell membrane was enlarged and dropping of the membrane completed either by further gentle suction or, preferably, by gravity as recommended by Burnet \& Faris (1942).

Second candling. After the membranes had been dropped the eggs were again candled and any showing signs of haemorrhage were discarded. This second candling can only usefully be carried out on white clear-shelled eggs, but if it is omitted a higher incidence of non-specific lesions must be expected with consequent wastage of experimental results.

\section{Inoculation}

After the second candling, a second cut was drilled through the shell close beside the first, and through this the inoculum was introduced onto the membrane. This second cut, as was noticed also by Overman \& Tamm (1956), prevented back-leakage of the inoculum around the needle. Inoculation was carried out using a $1 \mathrm{ml}$. tuberculin syringe to introduce $0.1 \mathrm{ml}$. of fluid and the egg was then gently rocked to distribute the inoculum.

All fluids inoculated contained $250 \mathrm{units} / \mathrm{ml}$. of penicillin and $25 \mu \mathrm{g} / \mathrm{ml}$. of streptomycin.

\section{Incubation}

The inoculated eggs were incubated at $36^{\circ} \mathrm{C}$. in commercial hatching incubators for $48 \mathrm{hr}$. It was not found necessary to seal the eggs after inoculation.

\section{Harresting}

The dropped area and surrounding membrane were harvested by cutting round the shell with scissors in the long axis of the egg and stripping the membrane from the shell. Pocks were counted by oblique lighting against a dark background.

\section{EXPERIMENTAL}

The first step in the elimination of the excessive scatter from counts obtained from a single virus dilution lay in the detection of those conditions of the membrane which led to spuriously low counts. Once such conditions could be recognized 
with certainty, all membranes showing them could be legitimately discarded. The observations of Burnet \& Faris (1942) were fully confirmed that the presence of a non-specific lesion anywhere on the membrane depressed the count, and it was further observed that a high non-specific lesion rate was accompanied by a high death-rate amongst the inoculated embryos. A second factor, which was found to exert an even more marked effect, was encroachment by the albumin sac on the dropped area of the membrane. This effect is clearly seen from the results of a single experiment in which a mean count of $39 \cdot 2$ was obtained from twenty-six control membranes, as contrasted with a count of $4 \cdot 3$ obtained from fifteen membranes showing albumin-sac encroachment. It is possible that the 'nonresponsive membranes' noted by Burnet \& Faris (1942) are related to this phenomenon.

Membranes with non-specific lesions or encroachment of albumin sacs were therefore discarded before counting from all the experiments reported below. Certain other rejects were also made. These included all damaged eggs, membranes showing signs of haemorrhage and membranes with any other abnormality. All estimates were in fact made on unblemished membranes only.

The next step in the experimental approach was governed by early difficulties when much work was vitiated, not only by the large scatter, but also by a high incidence of non-specific lesions and a high death-rate amongst inoculated embryos. The investigation was therefore arbitrarily divided into an examination, first, of those factors which influenced the egg, and, secondly. of those factors which influenced the virus count.

\section{Factors influencing the egg}

It has been generally accepted that the appearance of non-specific lesions on the membrane is due to mechanical trauma, and the technique for dropping membranes devised by Nadeje et al. (1955) was designed specifically to eliminate such trauma. Close examination of lesions, however, showed that they did not by any means always occur beneath the drill hole, nor were they always accompanied by signs of haemorrhage. Possible causative factors other than trauma were therefore considered.

\section{Composition of the dropping fluid}

When this investigation started it was customary, for reasons of virus stability. to use Hendry buffer with the addition of $10 \%$ normal horse serum for all virus dilutions. For the sake of uniformity and convenience the same buffer was used as the dropping fluid for the preliminary dropping of the egg membranes. In Table 1 are shown the results of an experiment in which Hendry buffer was compared, as dropping fluid, with Locke's fluid and two batches of normal saline. After the membranes had been dropped the eggs were incubated, without inoculation, for $48 \mathrm{hr}$. and then examined for the presence or absence of non-specific lesions.

This comparison led to the testing of the following range of fluids for this purpose: Hendry buffer, normal saline, McIlvaine buffer at $\mathrm{pH} 7 \cdot 2$ and $8 \cdot 4$, Earle's saline, Tyrode's, Ringer's and Locke's fluids, and veronal buffered saline. Most of these 
fluids were tested with and without the addition of $10 \%$ of normal horse serum.

It was found that Hendry buffer always caused a high incidence of lesions which was not influenced by the presence of serum. The other fluids appeared equally bland, giving a low incidence of lesions.

Table 1. Non-specific lesions produced by various dropping fluids

\begin{tabular}{|c|c|c|c|c|}
\hline \multirow[b]{3}{*}{ Lesions/eggs per group } & \multicolumn{4}{|c|}{ Dropping fluid } \\
\hline & Hendry buffer & Saline 1 & Saline 2 & Locke's fluid \\
\hline & $10 / 12$ & $4 / 12$ & $3 / 12$ & $3 / 12$ \\
\hline
\end{tabular}

A more restricted range of inoculating fluids was tested in eggs, the membranes of which had been dropped with normal saline. Hendry buffer, McIlvaine buffer and veronal buffered saline were tested with and without the addition of $10 \%$ of normal horse serum.

It was again found that Hendry buffer gave a high incidence of lesions as compared with the other fluids.

Hendry buffer is an isotonic mixture of di-sodium and sodium di-hydrogen phosphates, and an experiment was designed to determine whether its ionic composition was responaible for its toxicity. McIlvaine buffer, sodium phosphate and sodium-potassium phosphate buffers, all at $0.004 \mathrm{M}$ concentration in distilled water and $\mathrm{pH} 7 \cdot 2$, were tested factorially both as dropping and inoculating fluids. All gave a low incidence of lesions and no significant difference was observed between thern. The toxicity of Hendry buffer must, therefore, be due to its concentration rather than its ionic composition.

\section{Temperature of dropping and inoculating fluids}

In Table 2 are presented the results of an experiment in which normal saline at various temperatures was used as dropping fluid. The eggs were incubated without inoculation and the resulting lesions have been arbitrarily graded according to

Table 2. Effect of temperature of dropping fluid on reject rate in groups of 20 eggs

\begin{tabular}{|c|c|c|c|c|c|c|c|}
\hline \multirow{2}{*}{$\begin{array}{l}\text { Temperature } \\
\text { of dropping } \\
\text { fluid }\left({ }^{\circ} \mathrm{C} .\right)\end{array}$} & \multicolumn{3}{|c|}{$\begin{array}{l}\text { No. and grading } \\
\text { of lesions }\end{array}$} & \multirow[b]{2}{*}{$\begin{array}{l}\text { Total } \\
\text { lesions }\end{array}$} & \multirow[b]{2}{*}{ Dead } & \multirow[b]{2}{*}{$\begin{array}{l}\text { Total } \\
\text { rejects }\end{array}$} & \multirow[b]{2}{*}{$\begin{array}{c}\text { Clean } \\
\text { membranes }\end{array}$} \\
\hline & \pm & $+r_{+}^{+}$ & $+\underbrace{+}_{++}$ & & & & \\
\hline 0 & 22 & 3 & 5 & 12 & 5 & 17 & 3 \\
\hline 20 & 22 & 3 & 0 & 7 & 4 & 11 & 9 \\
\hline 37 & 41 & 2 & 0 & 7 & 0 & 7 & 13 \\
\hline 45 & 31 & 0 & 0 & 4 & 0 & 4 & 16 \\
\hline
\end{tabular}

severity. Twenty eggs were used at each temperature. This temperature effect was confirmed in other experiments. Table 3 is extracted from a factorial experiment 
in which four temperatures of dropping fluid were tested against three temperatures of inoculating fluid, the fluid in each case being saline. The high total incidence of lesions in this experiment was probably a seasonal effect.

Table 3. Effect of temperature of dropping and inoculating fluids on reject rate (Numerator $=$ no. of rejects. Denominator $=$ no of eggs per group.)

\begin{tabular}{|c|c|c|c|c|c|}
\hline & Tem & $\begin{array}{l}\text { of ino } \\
\text { uid ( }\end{array}$ & lating & & \\
\hline & 0 & 20 & 37 & Total & $\begin{array}{c}\text { Rejects } \\
\left(\begin{array}{c}0 \\
0\end{array}\right)\end{array}$ \\
\hline Temperature & & & & & \\
\hline 0 & $10 / 12$ & $8 / 12$ & $4 / 12$ & $22 / 36$ & 61 \\
\hline 20 & $7: 12$ & $5 / 12$ & 312 & $15 / 36$ & 42 \\
\hline 37 & $1 / 10$ & $5 / 9$ & 411 & $10 / 30$ & 33 \\
\hline 50 & $1 / 11$ & $2 / 12$ & $5 / 12$ & $8 / 35$ & 23 \\
\hline Total & $19 / 45$ & $20 / 45$ & $16 / 47$ & $55 / 137$ & - \\
\hline Rejects $(\%)$ & 42 & 44 & 35 & - & - \\
\hline
\end{tabular}

It can be seen that the temperature of the inoculating fluid was not critical except in so far as it interacted with that of the dropping fluid. When the temperature of the inoculating fluid was low. the temperature effect of the dropping fluid was exaggerated.

In none of the four experiments carried out, three of which were of factorial design, was there a striking difference in the reject rate over the range $20-50^{\circ} \mathrm{C}$., but the overall trend was always the same and, taken together, the results have been shown to be statistically significant. Further evidence on the effect of dropping fluid temperature will be considered later in relation to virus counts (p. 133).

It must be concluded that thermal shock is capable of causing the development of non-specific lesions. The results suggest that, even when the dropping fluid is initially at $37^{\circ} \mathrm{C}$., the cooling effect of evaporation on the small drop placed on the warm egg may reduce its temperature below that of the membrane before the two make contact. It is difficult otherwise to account for the apparent continuation of the decrease in reject rate into the higher temperatures.

The general conclusion from these results is that non-specific lesions may be caused not only by mechanical, but also by chemical and thermal injury, and that in the latter case the temperature of the dropping fluid is of more importance than that of the inoculating fluid.

\section{Age of embryos Factors influencing the virus count}

No significant difference was found in the counts obtained from embryos inoculated at the 11 th. 12 th and 13 th days of incubation. The reject rate, however, was high among the llth-day membranes owing to encroachment of albumin sacs on the dropped areas; and amongst the 13th-day membranes owing to development of non-specific lesions.

Embryos at the 12th day of incubation were. therefore, the most satisfactory for routine use. 


\section{Period of incubation of inoculated eggs}

In most laboratories eggs are incubated for 2 days following inoculation with vaccinia virus because the pocks are well developed in this time, and some strains of vaccinia are lethal to the embryo if incubation is further prolonged. Overman \& Tamm (1956) have recently, however, recommended a $72 \mathrm{hr}$. incubation period.

In an experiment to determine the optimum period of incubation, 80 eggs were inoculated from a single virus dilution and incubated at $36^{\circ} \mathrm{C}$. 26 eggs were removed on the first day after inoculation and 27 on each of the second and third days. The membranes were harvested and examined, and the pocks counted. There were no deaths amongst the embryos and no non-specific lesions on any of the membranes.

The pocks on the $24 \mathrm{hr}$. membranes were of about $0.5 \mathrm{~mm}$. diameter with hazy outlines, and were of similar density and appearance to herpes lesions. Being so small and indefinite they were very difficult to count. At $48 \mathrm{hr}$. the pocks measured 1-1.5 mm., were dense, white and raised, with sharp outlines and a central pin-point necrotic area. They were easy to count and the central necrosis permitted the identification of individual pocks even when they lay so close together that the surrounding reactions had amalgamated. No secondary lesions were present. By $72 \mathrm{hr}$. the pocks had enlarged to about $3 \mathrm{~mm}$. diameter; the central necrotic areas had enlarged and those of adjacent pocks had amalgamated. The outlines tended to be hazy and, where pocks lay close together, the intervening membrane had acquired a ground-glass appearance. Counting was consequently difficult and was further complicated by the presence of numerous secondary lesions dispersed over the entire membrane and not confined to the dropped area. The mean counts, with their fiducial limits, obtained from membranes harvested on the first, second and third days after inoculation. were $28 \cdot 0 \pm 5 \cdot 0$, $61 \cdot 4 \pm 4.4$ and $35 \cdot 9 \pm 3.4$ respectively. The low count at $24 \mathrm{hr}$. might be expected, but that on the third day could only be due to the amalgamation of lesions recognizably discrete at $48 \mathrm{hr}$. This effect of prolonged incubation could only be overcome by reducing the number of pocks on the membrane, and led Overman \& Tamm (1956) to state that counting could legitimately be carried out only below a mean count of 20 pocks per membrane. The effect of such a limitation on the precision of the technique is considered below (p. 135).

These observations are limited to the strain of virus in use in this laboratory, and the optimum period of incubation will be subject to the effects of strain variation, but the development of lesions as here described accords well with the observations of previous authors (Keogh. 1936; Burnet \& Faris, 1942). It is therefore likely that an incubation period of $48 \mathrm{hr}$. will be found to be optimum for most strains of vaccinia virus.

\section{Variation in delay between dropping of membranes and inoculation of eggs}

The time allowed to elapse between dropping the membranes and inoculating the eggs is liable to vary according to the number of eggs to be prepared and the usage of the particular laboratory. This would be unimportant if the sensitivity of the 
membranes remained unchanged, but clear-cut evidence of change in sensitivity after dropping of the membranes has been obtained, and this makes it necessary that the interval should be controlled.

Early experiments suggested some irregularity in response during the first few hours after the membranes had been dropped, as is shown in Expts. 1 and 3 of Table 4. The differences noted were statistically significant only in Expt 3, and

Table 4. Effect of varying intervals of time betceen dropping membranes and inoculating eggs

\begin{tabular}{cccccc} 
Interval & \multicolumn{5}{c}{ Mean counts } \\
\cline { 2 - 6 } (hr.) & Expt. 1 & Expt. 2 & Expt. 3 & Expt. 4 & Expt. 5 \\
0 & 46 & 26 & 55 & 50 & 45 \\
1 & 68 & 25 & - & - & - \\
2 & 67 & 20 & - & 58 & - \\
3 & 41 & 23 & 125 & - & 60 \\
4 & 57 & 18 & $-\ldots 0$ & - \\
5 & 49 & 13 & - & - & - \\
6 & 45 & 11 & 37 & 49 & - \\
24 & - & - & 22 & - & 22
\end{tabular}

our technique at the time was not sufficiently precise to allow of confident investigation. In most of the work reported in this paper, therefore, inoculations were made between 2 and $4 \mathrm{hr}$. after dropping the membranes, in the hope that in that period they would have settled to a steady response.

The effect of variation in delay was later re-investigated with more precise technique. As in the earlier experiments, single batches of eggs were divided into groups and the membranes of each group dropped at various intervals of time. All groups were then inoculated together from a single virus dilution. Dilution error between groups was thus excluded and significant differences between the mean counts must reflect differences in sensitivity between the groups. The results are shown in Expts. 4 and 5 of Table 4. Each group in these two experiments consisted of 20 eggs. The differences observed in Expt. 4 are significant at the $5 \%$ level, while those in Expt. 5 are highly significant. It must be concluded that there is in fact an irregular fluctuation in response, with peak sensitivity occurring between 1 and $4 \mathrm{hr}$. after the membranes are dropped. Presumably the count obtained at the peak gives the best estimate of concentration. The same virus suspension was used in Expts. 4 and 5, the experiments being performed on different days. It will be noted that the mean counts obtained at the periods of peak sensitivity correspond very closely. Since. however, both the occurrence and timing of the peak is unpredictable this fact can hardly be utilized. Direct comparisons of virus concentrations will not be affected provided that the delay is uniform throughout the groups of eggs used, but estimates of concentration obtained in different experiments will be affected, and an additional error introduced into the reproducibility of results.

In view of the tailing off of sensitivity evident in Expts. 2 and 3, the optimum period for inoculation would appear to be $1-4 \mathrm{hr}$. after dropping of the membranes. 


\section{Volume of inoculum}

It was found that similar counts were obtained whether the virus inoculum was introduced in $0 \cdot 1,0 \cdot 2$ or $0 \cdot 3 \mathrm{ml}$. volumes.

\section{Temperature of dropping and inoculating fuids}

In Table 5 are shown a series of virus counts extracted from the same factorial experiments as provided the data for Table 3. The differences in the mean counts are not significant. It may be concluded that, though the temperature of both fluids may affect the incidence of non-specific lesions, as is shown in Table 3,

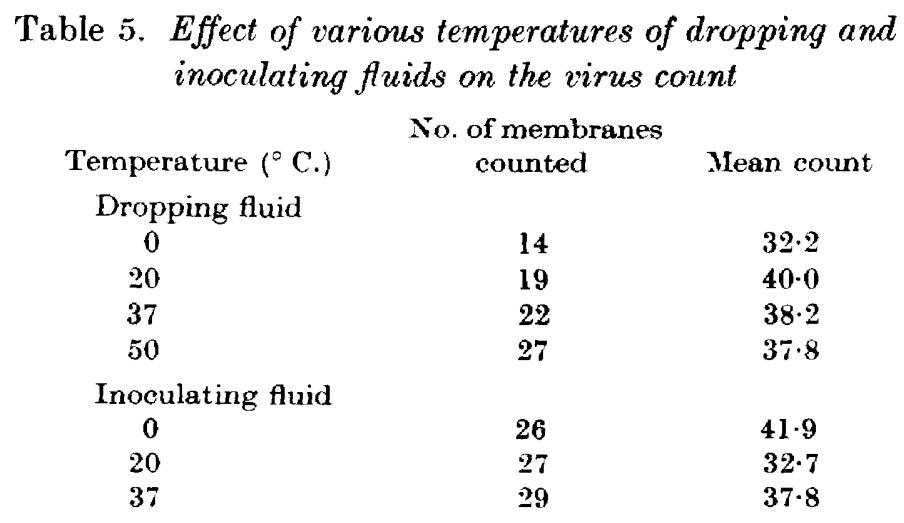

the mean virus count is not affected provided that unblemished membranes only are counted. This conclusion was supported by later work, but the experiment discussed in the next section indicated that the temperature of the dropping fluid might affect the distribution of individual counts, and therefore the precision of the result. without altering the mean count.

\section{Testing of general conclusions}

The results so far obtained indicated that several factors could contribute to the basic scatter of the technique through their effects on the egg membrane, but that. once these were controlled, the mean virus count was little affected by most of the other factors tested. Most of these factors had. however, been tested individually and their possible interactions were not known. An experiment was therefore designed to test factorially those conditions which seemed to be most important.

The factors selected for testing were dropping fluid temperature, dropping fluid composition and inoculating fluid composition.

The dropping fluids were used at three temperatures, 0,20 and $50^{c} \mathrm{C}$. ., and three fluids, Hendry buffer. McIlvaine buffered distilled water, and McIlvaine buffered distilled water with the addition of $10 \%$ of normal horse serum. were used both as dropping and inoculating fluids.

Since the experiment involved twenty-seven different treatment combinations. much care had to be taken to ensure that differences in the handling of different 
batches of eggs were eliminated as far as possible. Two hundred and seventy 12-day embryos from one batch were used in groups of ten. The virus dilutions were made up and stored for $2 \mathrm{hr}$. at $2^{\circ} \mathrm{C}$. prior to inoculation, other experiments having shown that the virus was stable at refrigerator temperature for this length of time. The delay between dropping and inoculation was fixed at $4 \mathrm{hr}$., this long interval being chosen so that small differences in the speed of inoculation should not appreciably affect the tot,al interval in individual batches of eggs. The results of this experiment, which are given in Table 6 , were examined by an analysis of variance.

Table 6. Factorial experiment testing dropping fluid temperatures against dropping fluid and inoculating fluid compositions

\begin{tabular}{|c|c|c|c|c|c|c|c|c|c|c|c|c|c|c|c|}
\hline \multirow{2}{*}{$\begin{array}{l}\text { Tempera- } \\
\text { ture of } \\
\text { dropping } \\
\text { fiuid } \\
\left({ }^{\circ} \mathrm{C} .\right)\end{array}$} & \multirow{2}{*}{$\begin{array}{l}\text { Composi- } \\
\text { tion of } \\
\text { dropping } \\
\text { fluid }\end{array}$} & \multirow{2}{*}{$\begin{array}{l}\text { Composi. } \\
\text { tion of } \\
\text { inoculating } \\
\text { fluid }\end{array}$} & \multicolumn{10}{|c|}{$\begin{array}{l}\text { Individual counts, } \\
\text { lesions and deaths }\end{array}$} & \multirow{2}{*}{$\begin{array}{l}\text { Mean } \\
\text { count }\end{array}$} & \multirow{2}{*}{$\begin{array}{c}\text { Coefficient } \\
\text { of } \\
\text { variation } \\
(\%)\end{array}$} & \multirow{2}{*}{$\begin{array}{c}\text { Probability } \\
\text { of fit with } \\
\text { Poisson } \\
\left(\begin{array}{c}0 \\
0\end{array}\right)\end{array}$} \\
\hline & & & 1 & 2 & 3 & 4 & $\tilde{5}$ & 6 & 7 & 8 & 9 & 10 & & & \\
\hline \multirow[t]{9}{*}{0} & $\mathrm{HB}$ & HB & 49 & 39 & 47 & 37 & $\mathrm{~L}$ & $L$ & $\mathrm{~L}$ & $\mathrm{~L}$ & $\mathrm{~L}$ & D & $43 \cdot 0$ & 14 & 49 \\
\hline & & BDW & 20 & 53 & 76 & 21 & 75 & 53 & $L$ & $\mathrm{~L}$ & $L$ & D & $49 \cdot 6$ & 50 & $<0.001$ \\
\hline & & SBDW & 29 & 22 & 35 & 34 & 17 & 19 & 25 & $\mathrm{~L}$ & $\mathrm{~L}$ & $\mathrm{~L}$ & $25 \cdot 9$ & 27 & 7 \\
\hline & BDW & HB & 21 & 25 & 15 & 27 & 38 & 46 & 30 & 25 & L & $\mathbf{T}$ & $28 \cdot 3$ & 35 & $<1$ \\
\hline & & BDW & 53 & 53 & 63 & 45 & 47 & 37 & 41 & 57 & 43 & 42 & $48 \cdot 1$ & 17 & 19 \\
\hline & & SBDW & 24 & 19 & 31 & 32 & 26 & 16 & 24 & 32 & 48 & 28 & $28 \cdot 0$ & 32 & 0.3 \\
\hline & SBDW & HB & 10 & $\tilde{\mathbf{5}}$ & 8 & 3 & 13 & 25 & 8 & $\mathrm{~L}$ & $\mathrm{~T}$ & $\mathrm{~T}$ & $10 \cdot 3$ & 70 & $<0.01$ \\
\hline & & BDW & 23 & 29 & 17 & 29 & 23 & 26 & 50 & 27 & $2 \cdot 2$ & 25 & $27 \cdot 1$ & 33 & $0 \cdot 2$ \\
\hline & & SBDW & 24 & 26 & 24 & 31 & 18 & 23 & 27 & 18 & 24 & 20 & $23 \cdot 4$ & 17 & 71 \\
\hline \multirow[t]{9}{*}{20} & НВ & HB & 42 & 48 & 35 & 54 & 30 & $\mathbf{L}$ & $L$ & $\mathrm{~L}$ & $L$ & $L$ & $41 \cdot 8$ & $\mathbf{2 3}$ & 6 \\
\hline & & BDW & 77 & 53 & 62 & 69 & 57 & 39 & 51 & L & $\mathrm{L}$ & $\mathrm{T}$ & $58 \cdot 2$ & 21 & 1 \\
\hline & & SBDW & 28 & 35 & 36 & 29 & 26 & 27 & 21 & 23 & $\mathbf{L}$ & $\mathrm{L}$ & $28 \cdot 1$ & 19 & 44 \\
\hline & BDW & HB & 31 & 28 & 36 & 26 & 14 & 31 & $\mathrm{~L}$ & $\mathrm{~L}$ & $L$ & $\mathbf{L}$ & $27 \cdot 7$ & 27 & 7 \\
\hline & & BDW & 39 & 62 & 46 & 52 & 67 & 54 & 44 & 46 & 60 & 42 & $51 \cdot 2$ & 18 & 8 \\
\hline & & SBDW & 33 & 23 & 28 & 18 & 22 & 22 & 28 & 15 & $3 \tilde{5}$ & 36 & 26.0 & 28 & 4 \\
\hline & SBDW & HB & 3 & 1 & 5 & 7 & 10 & 11 & 14 & 9 & 10 & 6 & $7 \cdot 6$ & 52 & 3 \\
\hline & & BDW & 30 & 38 & 31 & 27 & 27 & 38 & 25 & 23 & 47 & 36 & $32-0$ & 23 & 8 \\
\hline & & SBDW & 37 & 19 & 35 & 28 & 38 & 23 & 35 & 21 & 29 & 43 & $30 \cdot 8$ & 26 & 3 \\
\hline \multirow[t]{9}{*}{50} & $\mathrm{HB}$ & $\mathrm{HB}$ & 49 & 43 & 42 & 31 & 34 & 43 & 55 & 30 & $\mathbf{L}$ & $\mathbf{L}$ & $40 \cdot 8$ & 21 & 7 \\
\hline & & BDW & 69 & 47 & 60 & 51 & 53 & 61 & 5.5 & 44 & $\mathbf{L}$ & $\mathrm{T}$ & $55 \cdot 0$ & 15 & 30 \\
\hline & & SBDW & 18 & 32 & 26 & 28 & 20 & 31 & 28 & $\mathbf{L}$ & $\mathbf{L}$ & D & $26 \cdot 1$ & 20 & 36 \\
\hline & BDW & HB & 24 & 21 & 31 & 24 & $\mathbf{3 3}$ & 32 & 37 & $\mathrm{~L}$ & $\mathbf{L}$ & $\mathbf{L}$ & 28.9 & 20 & 30 \\
\hline & & BDW & 51 & 40 & 64 & 50 & 49 & 54 & 46 & 49 & 45 & 51 & $49 \cdot 9$ & 13 & $6:$ \\
\hline & & SBDW & $\mathbf{3 3}$ & 29 & 27 & 19 & 27 & 24 & 41 & 24 & 27 & $\mathrm{~T}$ & $27 \cdot 9$ & 22 & 20 \\
\hline & SBDW & HB & 8 & 4 & 9 & 17 & 11 & 4 & 13 & 16 & 10 & 6 & $9 \cdot 8$ & 47 & 3 \\
\hline & & BDW & 29 & 21 & 36 & 36 & 31 & 27 & 24 & 27 & 26 & 26 & $28 \cdot 3$ & 17 & 59 \\
\hline & & SBDW & 22 & 27 & 33 & 34 & 20 & 20 & 30 & 23 & 21 & 29 & 25.9 & 21 & 35 \\
\hline
\end{tabular}

$\mathrm{HB}=$ Hendry buffer. BDW = Icllvaine buffered distilled water; SBDW = Mellvaine buffered distilled wates' with $10 \%$ normal horse serum: $\mathrm{T}=$ technical reject (haemorrhage, etc.); $\mathrm{L}=$ non-specific lesion; $\mathrm{D}=\mathrm{desd}$ embry.

The results of this experiment may be summarized as follows:

\section{Factors influencing the egg}

(1) The deleterious effect of Hendry buffer is clearly shown. Where Hendry buffer was used there were 37 rejects from 150 eggs; where it was not used there were no rejects from 120 eggs. 
(2) When the dropping fluid temperatures were $0^{\circ}, 20^{\circ}$ and $50^{\circ} \mathrm{C}$. there were 15,13 and 9 rejects respectively. The differences are not significant but the trend fits previous findings.

\section{Factors influencing the virus count}

(1) Variation in temperature of the dropping fluid did not affect the mean count, the mean counts at the three temperatures being $30 \cdot 79,32 \cdot 71$ and $32 \cdot 18$.

The last column of Table 6, however, indicates a possible effect on the precision of the results, since only in the $50^{\circ} \mathrm{C}$. group is there a uniformly high probability of fit with the Poisson series. Although the gradation in precision looks clear-cut in the table, it is statistically significant only at the $10 \%$ level, so cannot be regarded as more than suggestive. Nevertheless we act upon it and, where the highest precision is necessary, membranes are dropped with fluid at $50^{\circ} \mathrm{C}$.

(2) The presence of serum, whether in the dropping or inoculating fluid, uniformly depressed the virus count. This effect is shown in Table 7.

Table 7. Effect of serum on the virus count

\begin{tabular}{|c|c|c|c|}
\hline \multicolumn{4}{|c|}{ (Extracted from Table 6) } \\
\hline & $\begin{array}{l}\text { Mean } \\
\text { Count }\end{array}$ & $\begin{array}{l}\text { No. of } \\
\text { membranes }\end{array}$ & $\begin{array}{l}\text { Significance } \\
\text { of difference }\end{array}$ \\
\hline $\begin{array}{l}\text { Serum present } \\
\text { Serum not present }\end{array}$ & $\begin{array}{l}23 \cdot 94 \\
44 \cdot 28\end{array}$ & $\begin{array}{r}138 \\
89\end{array}$ & Very high \\
\hline
\end{tabular}

(3) A highly significant but inexplicable interaction was observed when McIlvaine buffer, with or without serum, was used as dropping fluid and Hendry buffer as inoculating fluid. This effect is shown in Table 8.

Table 8. Interaction between McIlvaine buffered distilled water as dropping fluid and Hendry buffer as inoculating fuid

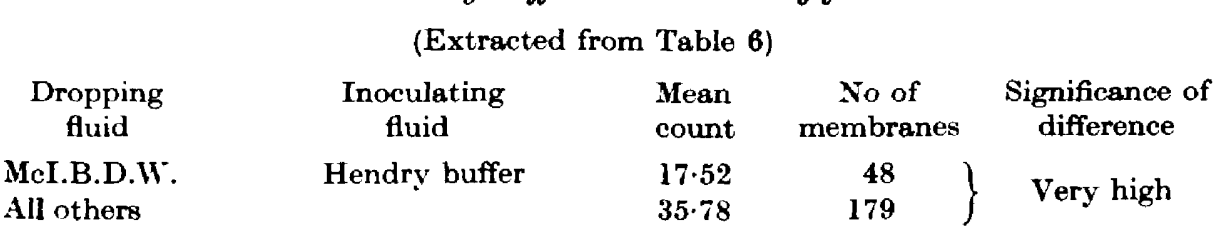

(4) In the figures shown in the last column of Table 6 there is a strong suggestion that, under ideal conditions, the distribution of counts will conform to the Poisson series. The importance of this suggestion is discussed later (p. 137).

(5) It may finally be concluded that both the dropping fluid and the fluid used for suspending the virus should be chosen with care, both because of their individual effects and because of their possible interaction. The dropping fluid should not be used straight from cold storage. 
Composition of the suspending fluid

The composition of the suspending fluid for virus titrations is normally determined by the necessity for protecting the virus from inactivation, and the inclusion of $10 \%$ of normal serum has for many years been a routine procedure for this purpose. The protective effects of various substances have been examined in the past (Skinner \& Bradish, 1954; Dick \& Taylor, 1949) and are outside the scope of this paper, but the results of the experiment considered in the previous section show that the composition of the suspending fluid may exert an effect on the virus count quite apart from failure of protection. We can offer no explanation of the McIlvaine buffer-Hendry buffer interaction, particularly since there was no apparent effect when the roles of the two fluids were reversed. The effect of serum, however, is probably due to the presence of neutralizing substances, specific or non-specific. A survey of normal horse sera has not been carried out, but the only two other sera tested have also been found to reduce the count when present in $10 \%$ concentration. This is shown in Table 9 in which are presented the results of a comparison between five suspending fluids. The tryptic meat digest broth (TMB) and peptone were diluted to contain the same amount of total nitrogen as $10 \%$ horse serum, the TMB being used at $25 \%$, and the peptone at $1 \%$, concentration in McIlvaine buffer. The horse sera were diluted in the same buffer. The virus suspensions were held at $2^{\circ} \mathrm{C}$. for $2 \mathrm{hr}$. prior to inoculation.

Table 9. Effect of various suspending fluids on the virus count

\begin{tabular}{|c|c|c|c|}
\hline $\begin{array}{l}\text { Suspending } \\
\text { fluids }\end{array}$ & $\begin{array}{l}\text { No of } \\
\text { membranes }\end{array}$ & $\begin{array}{l}\text { Mean } \\
\text { count }\end{array}$ & $\begin{array}{l}\text { Coefficient of } \\
\text { variation }\left({ }^{\circ},\right)\end{array}$ \\
\hline BDW & 16 & $73 \cdot 2$ & 24 \\
\hline T.МВ & 19 & $70 \cdot 8$ & 22 \\
\hline Peptone $1 \%$ & 15 & $69 \cdot 5$ & 16 \\
\hline Horse serum 1 & 16 & $43 \cdot 0$ & 23 \\
\hline Horse serum ? & 17 & 45.7 & 19 \\
\hline
\end{tabular}

BDW = MeIlvaine buffered distilled water, 0.004 $\mathrm{M}, \mathrm{pH}$ 7.2. T.MB = Tryptic meat broth, $25 \%$ in BDW. Horse sera were at $10^{\circ}{ }_{0}$ concentration in BDW.

The reduction in count by the two horse sera is highly significant. The effects of different concentrations of normal horse serum are shown in Table 10. A significant reduction in count is seen even at a 120 dilution.

Table 10. Effect on virus count of different concentrations of normal horse serum

\begin{tabular}{|c|c|c|c|c|c|}
\hline & & & erum & ratio & \\
\hline & $\begin{array}{l}\text { No. } \\
\text { serum }\end{array}$ & $1^{\circ}$ & 20 & 50 & $100_{0}^{\circ}$ \\
\hline Mean counts & $55 \cdot 9$ & $54 \cdot 9$ & $49 \cdot 5$ & $34 \cdot 8$ & $2 x \cdot 2$ \\
\hline $95{ }^{\circ}$ limits $=$ & $4 \cdot 3$ & $5 \cdot 7$ & $\pi \cdot 2$ & $4 \cdot 2$ & $5 \cdot 4$ \\
\hline No of membranes & 16 & 15 & 13 & 14 & 16 \\
\hline
\end{tabular}

Neutralization by normal serum has been demonstrated in the past in various serum-virus combinations; the evidence has been summarized by Dick \& Taylor 
(1949), but we are not aware that normal horse serum has previously been incriminated in combination with vaccinia virus. Pereira (1954), however, found that this serum inhibited the multiplication of fowl plague virus in tissue culture.

As was stressed by Dick \& Taylor (1949) the greatest caution must be exercised in the use of sera in virus diluents, and experiments are now in progress to determine whether other substances will confer a similar degree of protection on vaccinia without affecting the virus count.

The nature of the inorganic diluent appears to be less critical. No difference was observed between normal saline, veronal buffered saline and distilled water buffered either with McIlvaine buffer, sodium phosphate or sodium-potassium phosphate buffers at $0 \cdot 004 \mathrm{M}$ concentration and $\mathrm{pH} 7 \cdot 2$

\section{Relationship of pock count to number of virus particles}

Owing to its marked effect on precision, the level at which the counting of pocks may legitimately be carried out is of great importance in the practical use of this method of titration. On a Poisson distribution, where the variance is equal to the mean, it is simple to estimate the expected precision at any level of counting. and in Table 11 the expected precision, expressed as the coefficient of variation, is compared with the observed precision over a series of counts from a single titration.

Table 11. Relationship of precision to level of counting

\begin{tabular}{|c|c|c|c|c|c|}
\hline $\begin{array}{l}\text { Arithmetic } \\
\text { relationship }\end{array}$ & $\begin{array}{l}\text { No. of } \\
\text { eggs }\end{array}$ & $\begin{array}{l}\text { Mean } \\
\text { count }\end{array}$ & $\begin{array}{c}\text { Expected* } \\
\text { coefficient } \\
\text { of variation } \\
\left({ }_{0}^{0}\right)\end{array}$ & $\begin{array}{l}\text { Observed } \\
\text { coefficient of } \\
\text { variation }\left({ }^{0}\right)\end{array}$ & $\begin{array}{c}\text { Probability }{ }^{\dagger} \\
\text { of fit }\left({ }^{0}{ }_{0}\right)\end{array}$ \\
\hline 2 & 9 & $4 \cdot 8$ & 45 & 43 & 55 \\
\hline 5 & 8 & $14 \cdot 1$ & 25 & $3 \tilde{5}$ & 5 \\
\hline 10 & 8 & $2 \cdot 2 \cdot 1$ & 21 & 34 & 1 \\
\hline 20 & 8 & $33 \cdot 2$ & 17 & 23 & 9 \\
\hline 30 & 8 & $66 \cdot 7$ & 12 & 14 & 23 \\
\hline
\end{tabular}

* The expected coefficient of variation calculated on the assumption of Poissonian distribu. tion of counts.

+ Percentage probability of fit of observed distribution with Poisson series.

It can be seen that. both in theory and practice, precision increases markedly as the level of counting rises.

The response of the membrane to increasing numbers of virus particles cannot. however, be linear since the chances of pocks being due to multiple infection must rise as the number of virus particles increases. Therefore it is necessary to know the point at which the deviation from linearity becomes significant relative to the error of the test. Mathematical models on which the deviation could be calculated. and a correction factor applied, are of little value since the necessary basic assumptions cannot be justified. Of greater significance are the experimental results presented in Fig. 1 . in which the results of twelve experiments are shown graphically. Expts. A to $\mathrm{E}$ were routine titrations of various virus suspensions using six to twelve eggs per dilution. while $\mathrm{F}$ to $\mathrm{L}$ were performed specifically to 
test the linearity of response. Fiducial limits have been indicated in Expts. K and $L$ in which the number of membranes used was large and the limits correspondingly small.

In Fig. $1 \mathrm{~A}$ the means lie on a smooth curve between the origin and $81 \cdot 5$, but it is possible to draw a straight line comfortably within the fiducial limits of all but the last two values.

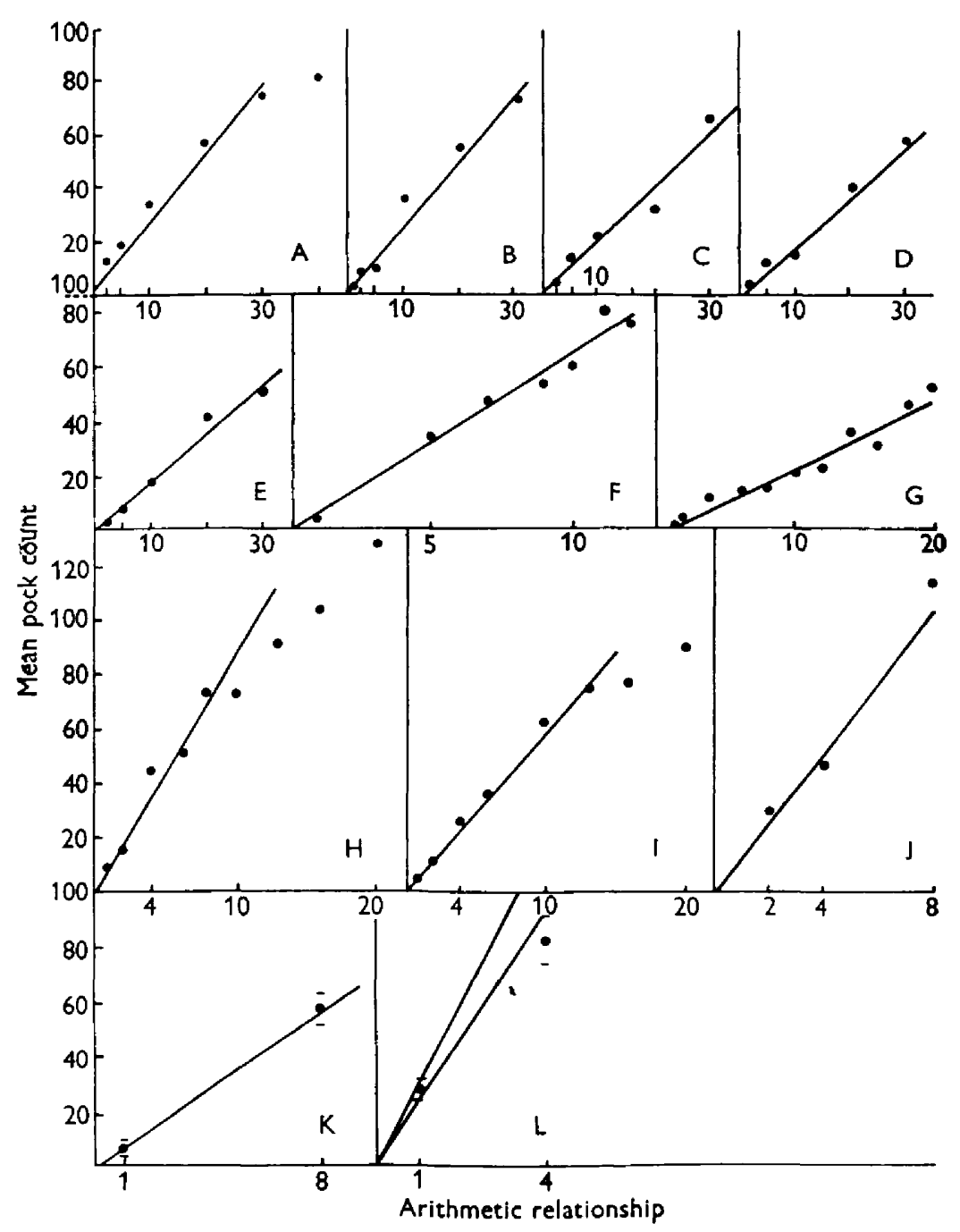

Fig. 1. Relationship of mean pock count to virus concentration.

In no other experiment is deviation detectable below a mean value of 70 pocks per membrane.

In some experiments the linear response continues beyond a mean count of 70 , but in others a sharp deviation occurs above this point, and we feel that counting above this level could not be relied on without a further improvement in the technique. However, if a mean pock count of 50 is aimed at by the technique 
described in this paper, the observed count may reasonably be expected to fall within the linear range at a level where the coefficient of variation should not exceed $25 \%$, that is, between 30 and 70 . Narrow fiducial limits to the mean may then be obtained without the use of a prohibitive number of eggs.

These results agree with those of Fenner \& McIntyre (1956), but not with those of Overman \& Tamm (1956), who found a mean count of 20 to be the upper limit of linear response. This discrepancy may be explained by the use, on the part of the latter authors, of a 3-day incubation period following inoculation of the virus.

\section{DISCUSSION}

When aliquot samples are taken from an evenly dispersed suspension of particulate material, we are told that the distribution of particles between samples follows the Poisson series. If, therefore, the pock count on egg membranes truly reflected the distribution of virus particles in the samples inoculated, they too should follow a Poisson distribution. Any departure from this distribution must necessarily imply a defect in the technique. and this is the view taken both by Reid, et al. (1949) and by Fenner \& McIntyre (1956). The last workers have accepted the excess scatter in the pock-counting technique as inevitable and have assumed that it is due to variation in susceptibility between eggs. No other obvious factor could be responsible, and fluctuation in sensitivity in groups of eggs can be demonstrated experimentally (Table 4). Variation in susceptibility between eggs can, however, be reduced. The effects of non-specific lesions and encroachment of the albumin sac on the dropped area are clear-cut, but they represent extreme cases of trauma and faulty candling respectively. Since the presence of a nonspecific lesion and decrease in membrane sensitivity are more likely to be associated as dual results of trauma rather than as cause and effect, decreased sensitivity may also be expected from trauma which falls short of that necessary to produce a lesion. Such an effect could be detected only by an increased spread in the results.

The improvement in the technique which followed our attempts to eliminate all factors tending to produce non-specific lesions led to markedly increased precision, coefficients of variation of less than $25 \%$ being consistently obtained provided that the mean count was higher than 30 . This degrees of scatter is still in excess of that expected on a Poisson distribution, but it can be seen from some experiments, particularly those shown in Tables 6 and 11. that good fit with Poisson distribution can be achieved. Such results encourage the hope that the method may yet be improved to the point where consistently Poissonian distribution may be expected.

This goal is of more than theoretical importance. When the variance of a technique is known the number of measurements needed to secure any desired degree of precision can easily be calculated from the relationship $V \bar{x}=V / n$, where $V \bar{x}$ is the variance of the mean, $V$ is the variance of the individual observations, and $n$ is the number of observations. In the present instance $n$ represents the number of membranes counted. To give any single value for $V \bar{x}$, therefore, the value of $n$ must vary directly with the value of $V$. If pocks are counted at the 
50 level $V=50$ on the Poisson distribution, but usually lies between 100 and 150 on the observed distribution, giving a coefficient of variation of $20-25 \%$. In any one experiment the precision actually achieved must, of course, be estimated from the results themselves, but in planning an experiment the larger variance would have to be expected. Therefore, to obtain a predetermined variance to the mean, three times the number of eggs must be used than would be necessary if Poissonian distribution could be relied on.

For instance, in one experiment in which Poissonian distribution was achieved, it proved possible to distinguish between two virus suspensions with concentrations of $1.94( \pm 0 \cdot 17) \times 10^{10}$ and $1 \cdot 60( \pm 0 \cdot 14) \times 10^{10} \mathrm{i} . \mathrm{u}$. per ml. These estimates with their narrow fiducial limits were based on the results from five closely spaced dilutions of each suspension, involving 38 and 34 eggs respectively, and were calculated by the standard method of weighted means. With the degree of variation more frequently achieved this degree of precision would have required the use of over 100 eggs for each titration.

A further effect of excessive scatter needs emphasis. The contention of Burnet \& Faris (1942) that departure from the expected scatter is usually towards a low rather than a high count is fully justified by the demonstrable effects of nonspecific lesions and albumin-sac encroachment. When scatter is excessive, therefore. estimates of virus concentration will always tend to be low, and this must be borne in mind when comparisons are made between the sensitivity of this and other methods of titration.

\section{SUMMARY}

A detailed investigation has been made of the pock-counting method for titrating raccinia virus on embryonated eggs with a view to eliminating the wide scatter of results hitherto inseparable from the technique. and of assessing the precision of which it is capable. A detailed description is given of the technique evolved.

Reasons are given for supposing that the distribution of counts should follow the Poisson series, and considerable progress is claimed towards the achievement of such a distribution.

The authors wish to acknowledge their 'indebtedness to $\mathrm{Mr} \mathrm{S}$. Peto for his invaluable advice on the statistical aspects of this work. for his help in the planning of experiments and for the evaluation of the experimental results. They also acknowledge with gratitude the expert technical assistance of Miss Hilary J. Way and $\mathrm{Mr}$ D. J. Algar whose enthusiasm has contributed greatly to this work.

\section{REFERENCEN}

Beveridge, W. I. B. \& BikNet, F. M. (1946). The cultivation of viruses and rickettsiae in the chick embryo. Sper. Rep. Ser. med. Res. Coun., Lond., no. 256.

BCrnet, F. M. (1936a). Immunnlogical studieg with the virus of infectious laryngotracheit is of fowls using the developing egg technique. J. exp. Med. 63, 685.

Burxet, F. I. (1936b). The use of the developing egg in virus research. Spec. Rep. Ser. med. Res. Coun., Lond., no. 220.

Burnet, G. M. \& Faris, D. D. (1942). The techniques of quantitative chorioallantoic virus titration. .J. Bact. 44, 241. 
Clarke, W. M. (1928). The Determination of Hydrogen Ions. 3rd ed. p. 214. London: Baillière, Tindall and Cox.

Dick, G. W. A. \& TAYLoR, R. M. (1949). Bovine plasma albumin in buffered saline solution as a diluent for viruses. $J$, Immunol. 62, 311 .

Fencer, F. \& McIstyre, G. A. (1956). Infectivity titrations of myxoma virus in the rabbit and the developing chick embryo. J. Hyg., Camb., 54, 246.

KEOGH, E. V. (1936). Titration of vaccinia virus on the chorioallantoic membrane of the chick embryo and its application to immunological studies of neurovaccinia. J. Path. Bact. 43. 441.

Nadeje, T., Tamm, I. \& Overmax, J. R. (1955). A new technique for dropping the chorioallantoic membrane in embryonated chicken eggs. J. Lab. clin. Med. 46, 648.

Overman, J. R. \& TAMM, I. (1956). Quantitative titration of vaccinia virus on the chorioallantoic membrane. J. Immunol. 76, 228.

Perema. H. G. (1954). The use of suspensions of isolated cells for the study of the factors affecting the multiplication of fowl-plague virus. J. gen. Microbiol. 10, 500 .

REID, D. B. W. CRAwleY, J. F. \& Rhodes, A. J. (1949). A study of fowl pox virus titration on the chorioallantois by the pock counting technique. J. Immunol. 63, 165.

Skinfer, H. H. \& Bradish, C. J. (1954). Exposure to light as a source of error in the estimation of the infectivity of virus suspensions. J. gen. Microbiol. $10,377$.

Woodruff, A. M. \& Goodpasture. E. W. (1931). The susceptibility of the chorioallantoic membrane of chick embryos to infection with the fowl-pox virus. Amer.J.Path. 7, 209.

(MS. received for publication 23 . VII. 56) 